\title{
The Norwegian Report on Population Development
}

\author{
MERETE HAGAN
}

\section{Introduction, assignment and committee composition}

The background for the appointment of a population committee may be found in the Norwegian government's long-range plan for 1982-1985. In the plan it was stated that the age structure of the population will change considerably during the next decade, and that this may have great impact on social development. This statement resulted in the desire, on the part of the government, to research the issue of population development in depth. A committee was appointed in August 1981 and was assigned a three-fold task with the following main points:

1. Based on recent national and regional population development, the committee was directed to compile a survey of possible sociological, economic, psychological and/or other factors to which the noted development could be attributed.

2. The committee was to discuss the social and economic consequences of a number of various possible developments in population size and composition, in general and by district, in the areas of education, housing, labor supply and demand, health care and social work, etc. Furthermore the committee was directed to evaluate possible measures which could possibly be implemented to reduce the problems for society which could arise as the result of the various courses of population development. Great emphasis would have to be attached to evaluating the abilities of and possibilities for the public sectors to adjust to the various development courses. Immigration is assumed to remain at its present level.

3. The committee was also directed to discuss whether it would be desirable or even possible for the government to actively influence population development. In this connection an evaluation should also be made of public actions which could influence population development, based on a positive environment for children and adolescents, equal rights and equal opportunity between the sexes, and which would pay special attention to the situations of the elderly and of families with children.

Upon taking a closer look at this assignment, it becomes evident that is very extensive. The most easily accessible material was that which described the phenomenon mentioned in item 1 of the assignment. Item 2 on the list asked for a consequent analysis of the areas of society in which the public sectors have wide-ranging responsibilities. There were very few analyses available about the consequences entailed by the expected population development. Item 3 on the list is intended to lay the foundation for a political discussion about whether it would be possible and desirable to formulate a population policy in Norway 
and/or whether measures grounded in the desire to influence population development ought to be initiated.

The committee was composed of three representatives with university research backgrounds, three representatives from political parties, a representative from the employers' associations and one from the employees' organizations, one from county administration, one from the Central Bureau of Statistics and four from various ministries. The secretary of the committee was Bjørg Moen from the Central Bureau of Statistics.

The work of the committee was to be concluded by the end of 1983 . Unfortunately the final completion work has taken longer than expected, and there was a desire for a popular edition of the report. For these reasons this report is not yet printed as I had hoped it would be when I was assigned this task at the seminar. The present introduction is therefore as brief a presentation of the whole report as possible - a task I have found difficult due to the fact that the core material is very voluminous. This also means that many issues have been reported with »a lick and a promise», since it has been most natural for me to concentrate primarily on the issues which concern the consequences, with special emphasis on the welfare, health care and social service sectors where I have my background.

\section{The historical development of population and fertility}

The recent development of the population, both nationally and regionally, is fully described. Statistics are given for

- birth rate and birth surplus developments

- mortality rate development

- changes in regional population distribution

- changes in patterns of migration

- age distribution of the population

- family distribution of the population

I see no point in presenting the figures which concern population development in this context, but I would like to point out three development trends which have been of great importance during the recent discussions of the consequences of population development.

Firstly:

Population growth has declined in Norway. If we base our perspective on the past 40 years, the population of Norway surpassed 3 million in 1943 and 4 million in 1975 . The growth declined from a $9.6 \%$ increase in the decade from 1951-1960 to $8.2 \%$ the following decade and $5.2 \%$ during the 1970 s.

\section{Secondly:}

The reduction in population growth is due to a reduction in fertility. Nonetheless the birth rate has shown great fluctuations. Up until 1936 the birth rate dropped. Then there was a strong increase, peaking in 1946. The birth rate, however, remained high until the end of the 1960 s when there was a steep decline. Since the end of the 1970 s, this decline has leveled out.

\section{Thirdly:}

There have been relatively great changes in the age structure of the population since 1960 . The changes have been especially great among the youngest and oldest age groups. While children under the age of 10 comprised $17 \%$ of the 
population in 1960 , their share had sunk to $14 \%$ in 1980 . For the age group 70 and over the share was $7 \%$ in 1960 and $10 \%$ in 1980.

A detailed description of fertility development from the 1870 s up to the present time, as well as a survey of the development of fertility patterns in Norway is presented in the report. I will attempt to summarize some of the main conclusions of this description:

The description is based on the developments experienced in western countries during the past 200 years and which are normally designated as the demographic transition. The transition has four phases:

1. The high stationary phase, where both birth and death rates are high, but the birth rate is a little higher in order to ensure a certain population growth.

2. The early expanding phase, where the population begins to grow, at times even explode, as a result of a stable birth rate and a rapidly declining death rate.

3. The late expanding phase, where the growth rate is slowed as the death rate stabilizes at a low level and the birth rate declines.

4. The low stationary phase, where birth and death rates are stabilized at low levels and are nearly in balance. This is the zero-growth phase which has not yet come to pass. Some people are of the opinion that it will never come to pass, but rather that the last phase in the transition will fluctuate.

Looking at the western countries in general, the parallels in their developments during the period from 1870 to 1935 are striking. The exceptions are Spain, Portugal and Italy which lagged approximately 20 years behind. In the other countries declines in family size occurred at the same time and same pace. Even though the mass production of contraceptives began at the end of the $1870 \mathrm{~s}$, special investigations have shown that the traditional methods of birth control are in use even up to our own time. This indicates that the motives for reducing the number of children have been more important than the means.

The decline in the birth rate turned to an increase in 1935. This upswing was completely unexpected and occurred simultaneously in all of the western countries and in all generations from before 1920, while for the generation after 1920 there were three general trends. Broadly speaking, this led to a convergence in the birth rate for European countries and leveled out the differences between them. North America was an exception for there the birth rate continued to rise.

The most important common characteristic of the development was family size. There were fewer childless and 1-child-families, and the larger families decreased in size or remained stable. Two- and 3-child-families became the standard.

\section{Possible explanations}

There is a relatively comprehensive section in the report which provides a survey of possible explanations of the birth rate development. The discussion is based on a model which classifies the explanation variables into »intermediate» and »basic» variables, although the distinction is not always clear. Factors which influence the chances for intercourse, factors which influence the chances of becoming pregnant, and factors which influence the course of a pregnancy, belong to the intermediate group of variables. The basic factors are variables which influence the intermediate factors and through them, influence fertility.

The intermediate variables discussed are

- marriage

- cohabitation

- the dissolution of marriage/cohabitation 
- birth control

- induced abortion

In this context, however, I will not go into more detail concerning development with reference to these factors, but I do recommend that those persons who are especially interested in this topic read the report itself when it is completed.

The basic factors mentioned are

- educational tendencies

- the career activity of women

- housing and location conditions

- cultural changes

- changes in attitudes and norms

A majority of these explanatory factors have undergone great changes, changes which to a great extent were concurrent with drops in the birth rate. It is, therefore, reasonable to view the birth rate declines in connection with the changes, although we cannot, on this basis, state with certainty that changes in certain factors have been the direct causes of the drops. It is, on the other hand, clear that the birth rate development in itself has influenced changes in a number of the explanatory factors. The direction of the influence between the factors has probably alternated over time and between groups of women.

At the end of the chapter the most well-known fertility theories and models are discussed, but I shall not consider them here.

\section{Population development in Norway until the year 2040}

As a basis upon which to evaluate the consequences of future population development, the committee commissioned population projections. Such projections predict how the population will develop in the future under certain conditions. The committee chose to work on the basis of the following premises:

- The death rate will be reduced by $1 \%$ per year for 10 years and subsequently remain constant

- Net immigration would be fixed at 4000 persons per year which is equal to the number of immigrants who entered Norway in 1981

- The fertility rate projections varied according to 4 alternatives:

- Alternative $H$ - the total birth rate is increased from 1.7 in 1981 to 2.1 in 1991 and is thereafter held constant for the remainder of the projection period.

- Alternative $K$ - the total birth rate remains constant at 1.7 as was observed in 1981.

- Alternative $L$ - the total birth rate is reduced to 1.46 in 1988 and thereafter remains constant.

- Alternative L-extra - the total birth rate is reduced to 1.33 in 1993 and thereafter remains constant.

In 1983 the birth rate in Norway fell to under 1.7 for the first time. Compared to Denmark, where the birth rate in 1981 was lower than alternative $\mathrm{L}=1.46$, this is high.

The committee has not pointed to one of the population projections as the most probable, but is of the opinion that the total birth rate will be within the two extremes mentioned in the alternatives represented by the total birth rates of 2.1 and 1.33 respectively. The possibility that the birth rate development can vary outside of these two extremes cannot be overlooked, however. The committee feels that there is not reason to believe that the birth rate would rise 
Fig u r e 1. Projected population of Norway.

Four alternatives

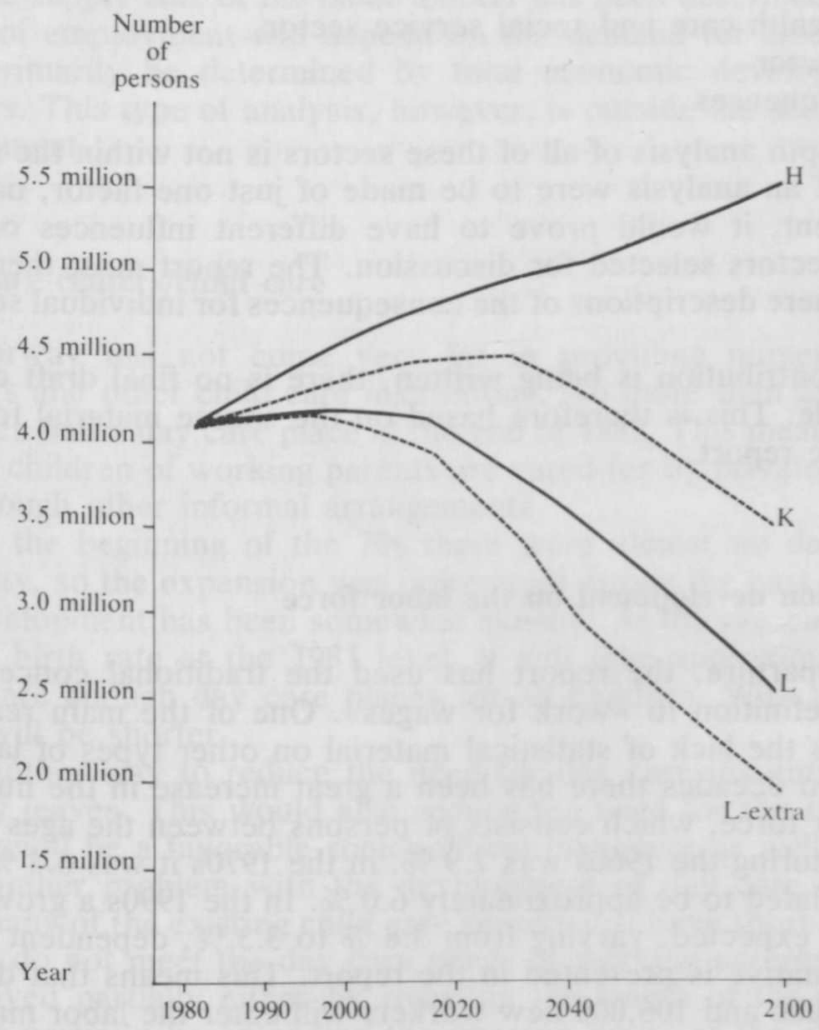

appreciably over such a short period of time unless extensive measures were implemented which would make it easier to have children in our society.

I do not find it expedient to discuss the population developments entailed by these projection alternatives here, but I will present a graph which illustrates the development of the total population up until the year 2100 . As may be seen on the graph, it is necessary to go all the way to the year 2010 before the various alternative fertility rates begin to influence the total population.

\section{Some connections between population and other social relations}

In a separate chapter there is a survey of some connections between population and other social relations. This survey serves as an introduction to the discussion of the consequences of population development.

An important goal for the report is just this, to point out relations which may be influenced by population development so that the various consequences may be incorporated into general social planning.

\section{The consequences of population development in different areas}

The committee discusses the consequences of population development in a chapter which is divided up into the following topics: 
1. Employment, the labor market, supply and demand

2. Day care centers

3. Education

4. The welfare, health care and social service sector

5. The housing sector

6. Regional consequences

Obviously an in-depth analysis of all of these sectors is not within the scope of this report. Even if an analysis were to be made of just one factor, namely population development, it would prove to have different influences on the various parts of the sectors selected for discussion. The report must therefore be fairly superficial where descriptions of the consequences for individual sectors are concerned.

At the time this contribution is being written, there is no final draft of the entire chapter available. This is therefore based on the source material for the relevant chapter in the report.

\section{The impact of population development on the labor force}

As its point of departure, the report has used the traditional concept of "labor", limiting its definition to "work for wages". One of the main reasons for such a limitation is the lack of statistical material on other types of labor.

During the past two decades there has been a great increase in the number of persons in the labor force, which consists of persons between the ages of 16 and 66 . The increase during the $1960 \mathrm{~s}$ was $7.9 \%$, in the $1970 \mathrm{~s}$ it was $6.4 \%$ and in the $1980 \mathrm{~s}$ it is calculated to be approximately $6.0 \%$. In the $1990 \mathrm{~s}$ a growth in the labor force is also expected, varying from $3.8 \%$ to $3.3 \%$, dependent upon which projection alternative is presented in the report. This means that during the 1990 s between 90,000 and 106,000 new workers will enter the labor market, dependent on the birth rate. After the turn of the century the size of the labor force will decrease in the period from 2000-2020 according to the prognoses for the two alternatives with the lowest birth rates, while it will remain more or less constant if the birth rate remains stable at its present level. During the period 2020-2040 the labor force will be considerably smaller. The size of the labor force will remain stable only if the birth rate stays at about 2.1. This means that until the turn of the century there will be a need for more jobs, while after the turn of the century we can expect a stagnation.

The number of jobs it will be necessary to create in order to meet the need of the population for paid employment, will be dependent on career frequencies. From 1970 to 1980 there was a strong increase in the career frequency of women, especially of married women. If, however, one considers the growth in the number of man-years of labor from 1970 to 1980 , it was small. In 1980 about 40,000 fewer man-years of labor were worked by men than in 1970 , while women worked nearly 75,000 more man-years than a decade earlier. The 1970 s represented a redistribution of labor among more people.

In order to arrive at estimates concerning the labor force of the future and the total number of working hours, MATAUK was used. MATAUK is the Central Bureau of Statistic's model for analyzing labor supply. The model can incorporate changes in demographic conditions, age, sex and marital status for women, in addition to changes in educational level and occupation.

Calculations about the percentage of the population which is employed have been made using two alternative projections; one projection is based on changes in working percentages and one has fixed working percentages. In a nutshell, the results showed that all of the alternatives would lead to increases in the working population until the year 2005 . For the alternative where the birth rate 
is assumed to remain stable at its present level, there will be a decrease in the working population after the year 2010 .

The supply side of the labor market has been described above. The development of employment will depend on the demand for labor. The demand again will primarily be determined by total economic development in the various sectors. This type of analysis, however, is outside the scope of the committee's assignment.

\section{Day care centers/child care}

Norway has not come very far in providing nursery schools, day care centers and other child care institutions. No more than $25 \%$ of pre-school age children had a day care place at the end of 1982. This means that a large number of the children of working parents are cared for by private babysitters, relatives or through other informal arrangements.

At the beginning of the 70 s there were almost no day care institutions in Norway, so the expansion was quite rapid during the past decade. Now the rate of development has been somewhat slowed. At the present rate of development and a birth rate at the 1981 level, it will take approximately 50 years before there are enough day care places for all children. With a lower birth rate the time will be shorter.

Another way to reduce the need for day care institutions is to extend maternity leaves. This would also reduce the need for the most expensive places and would be a favorable sociopolitical maneuvre as well.

Another problem with the development of day care centers in Norway is that many of the existing child care centers just have short-term places available. These do not meet the day care needs of working parents. This problem could be solved partially either by reducing the length of the parents' working day and/or partially be extending the opening hours of the child care centers, but these solutions would have great economic consequences.

Development has just begun of after-school day care centers for children who just attend school for a few hours each day, and the unmet needs in this area are undoubtedly great.

\section{Education}

School is mandatory in Norway for children between 7 and 15 years of age. As a result of the decline in the birth rate, a decline has already begun in the number of pupils in the primary and lower secondary grades. This decline will continue and in the period $1981-1990$ there will be nearly 100,000 fewer pupils, a reduction corresponding to $18 \%$.

After 1990 the number of pupils will vary in step with the birth rate during the next few years. The present birth rate will provide a considerably smaller number of pupils during the entire projection period than there were in 1981, but a birth rate of 2.1 would maintain pupil numbers at a level almost as high toward the end of the projection period as what we had in $1980-81$.

In the upper secondary school the number of students will also be very dependent upon the number of children born each year, since a great many of them continue their schooling after the mandatory period. Eighty-three \% of the pupils from the primary and lower secondary schools continue straight on to upper secondary education. The number of persons in the age group 16-18, which accounts for most of the students in upper secondary schools, will vary in the same way as the lower secondary school group, but with a three-year time lag. 
The increase will continue until 1985 when it will drop drastically and will already in 1990 be down to the 1970 level.

Approaching the year 2000 , there will be approximately 40,000 fewer persons in this age group than there were in 1985. This corresponds to a decrease of about $20 \%$ over a 15 -year period.

The number of children born in a particular year does not have the same effect on the number of students pursuing higher education as it has on the number of pupils engaged in primary and secondary education. In fact in the 1970 s there was a decrease in the number of upper secondary school graduates who went on to university. I will not go into the reasons for this here, but merely want to make the following point. The future interest of young people in further education will be decisive for whether we will be able to use our present educational capacity fully when the big reduction in the most important age groups begins during the 1990s.

Obviously, student mass reductions of the magnitude predicted over the next 15-20 years will lead to considerable changes in the educational sector. In Norway this sector is predominantly public. Even the operating costs of the few private schools in the country are financed primarily over government budgets. In light of the burden on government budgets which can be expected as a result of the coming boom of senior citizens, we can expect strict demands for severe cut-backs in the educational sector. Without a reduction in resource consumption, the unit cost per pupil will increase substantially. One great problem and challenge will be how to auspiciously use the investments represented by school buildings and teachers with long education.

\section{Health care, welfare and the social service sector}

From a general social perspective this sector will have the greatest economic importance. In the government and welfare budget for 1984 the cost of these sectors made up $33 \%$ of the government's total expenditures. In addition we have municipal and county spending in these areas. This illustrates the fact that the costs incurred in these areas will be of primary inportance for the public sector in general.

The report has attached importance to the areas where changes in population distribution and composition are expected to have especially great impacts. The report attempts to isolate the population component in these developments.

When a projection is to be made of the effects of population development on government actions, it is necessary to begin with the current solutions and the interaction of the various measures presently in effect. In several areas of the health care, social service and welfare sectors, however, clear goals resulting in structural changes in the services have already been postulated. An example of this would be the desire to reduce the growth of institutionalization and to concentrate on solutions which would offer "open" care. An isolated projection of these future needs on the basis of the present pattern of use would indicate a need for expansion which would be diametrically opposed to the abovementioned goal. The problem increases the further into the future the projection goes.

Parallel to the work of the population committee, a committee for the evaluation of public welfare financing has been in operation. This committee has examined the development of the welfare sector at a completely different level than the population committee, which had limited itself to forecasting the number of people who would require welfare benefits as a consequence of population development.

The population of Norway is supported by various sources. Only about $40 \%$ of the population live on their own wages although a larger percentage earn 
wages. In this context part-time work plays an important part. Those elements of the population which do not partially or completely support themselves by their own incomes, receive support from government budgets or privately from their families.

In the first group we find retired persons and persons of employable age who are experiencing a temporary or more longlasting loss of means of support due to personal loss of income or the loss of a supporter. Children, youths and many married women are supported privately through family incomes. As a result in the changes in population age composition, the number of persons entitled to government support will increase. If one looks at the projection period as a whole, in the period from about 1995 to 2010 there will be a slight decrease in the number of persons who, based on the present retirement age, will be entitled to old age pensions. Just the same the total picture is one where there is a big increase in the number of retired persons, from 525,000 in 1980 to 835,000 in 2040 , an increase of 310,000 persons. The average annual increase is still not more that $0.8 \%$, but the main burden of the increase will come during the years from 2010-2030. As the increase in the number of elderly persons grows, the number of children and in a few years of number of young people supported by their families will decline. With the increasing career frequency of women, this family support will also loose importance. We will be confronted with a marked shift from family support to public support of those groups of the population which are not involved in paid employment.

The development of the number of old age pensioners in the projection period is easily calculated and can be predicted with a high degree of probability. It would also be a simple matter to project the consequences of a reform such as the lowering of the retirement age. If, however, a more flexible solution such as part-time retirement were chosen, the consequences would be difficult to project. Then the development of the labor market would gain greatly in importance. This is also the case regarding the number of persons receiving disability benefits.

In the way the current welfare system is constructed, public authorities do not have very much opportunity to influence short-term expenses. For example, the supplementary retirement system established in 1967 will not be completed until 2007. The general pension level is only vulnerable to relatively long-term influence. Because of this it is necessary to present planners and politicians with the general population development trends at such an early stage that it is still possible to incorporate the consequences of these development trends into the more long-range strategies.

Welfare benefits include cash contributions to the population, while the health care and social service sectors are primarily responsible for financing, planning and operating the various health care and social services required by the population. The report has been especially concerned with the services considered to be public responsibilities.

The aging of the population will entail higher demands on health and social services. The reduction in the demand for services for children, young people and the working segment of the population will only marginally compensate for the increasing needs of the oldest age group which represents the greatest consumers of these services.

The projections show that the need for hospital and nursing home places will increase, and that there will be a need to change in the composition of the services (type of places) and geographic location of these places. This increased need stands out in contrast to the curbing of growth which is the present official policy.

The demand for other services such as general medical care and physical therapy do not show the same age variations. There is, however, reason to question whether the present pattern of consumption does not illustrate the 
demand for these services by the various age groups rather than representing a true expression of need.

Other services such as home nursing and home help are primarily intended for the elderly segment of the population. By concentrating on open care and expansion especially among the oldest of the old, there will be a considerable need for growth during coming years. Other factors point in the same direction. Studies show that today the greatest part of the elderlys' needs for help are met by the immediate family. This means that when more women go out to work and the number of women in the age group which provides care becomes smaller in relation to the number of the elderly, the family will be less able to provide care. More population mobility has somewhat the same effect.

In order to meet the challenge presented by increasing care needs in the projection period, it will be necessary to forge ahead on many fronts at the same time. It is necessary to discuss the relationship of the different kinds of care arrangements, with special emphasis attached to the role that the government can and ought to play in relation to private care sources. Care and the burdens of care should no longer be exclusively the responsiblity of women. Care must be distributed among more persons and a balance must be struck between public and private care in order to reduce the vulnerability of the system and the responsibility of the individual.

\section{Housing}

The impact of population development on the housing sector will be discussed in a separate section of the report, but the draft for this section is not yet available. Consequently I cannot discuss the issue further here.

\section{Regional consequences}

The committee has prepared a separate report discussing questions related to regional population development. I will content myself with just pointing out a number of the main points in the committee's report.

One main point was that it appears probable that most parts of the country will experience a positive natural growth rate until about the year 2000. Excluding the migration factor, the populations of most districts of Norway are self-perpetuating, although the central area of Eastern Norway will experience a decline in population.

Of course regional population development, the pattern of settlement, is extremely dependent upon net migration. Recent experience indicates that mobility has declined. Although there are multiple and complicated reasons for this, some of which may result from short-term economic fluctuations, there are still several signals which indicate that mobility will remain at its present low level. A number of these factors are mentioned in the committee report, but detailed discussions of these are beyond the scope of this summary. One important factor which could counteract the tendency of the settlement pattern toward stabilization, is the location of future new jobs. The number of persons of employment age will increase in more than $80 \%$ of the municipalities in Norway close to the year 2000, and if the geographic distribution of newlycreated jobs is not balanced, population development in outlying districts may be more negative than the situation portended in the years around 1980 .

In all of the projection alternatives the total population will increase until about the year 2000 . For the low and extra low birth rate alternatives the population decline will not occur until after the year 2020. This population decline does not mean that there will be fewer new people to distribute, but rather that deci- 
sions will have to be made about which regions shall lose population. Settlement pattern stability can easily be disturbed by a population drop - through a reinforcement of migration to urban areas resulting in a depopulation of large parts of provincial Norway.

\section{Measures to meet the impacts of population development}

In a separate chapter there is a discussion of the various sectors which were discussed earlier in connection with mapping the consequences of the population development. I will not go through the individual sectors once again, but will rather simply summarize the main points.

As a point of departure we can confirm that the population development we face will create extensive planning problems. During the coming years we will experience constant growth of the labor force. The economic development we experience today does not seem to provide for a considerable increase in the number of jobs, so employment problems seem imminent. In the long run the labor force will decline, based on the present birth rate or one even lower. The reduction in the labor force will occur at the same time as the number of pensioners and elderly people will increase.

In the educational sector there will be a great deal of empty capacity, first at the primary school level, and later at the higher levels.

In the health care, social service and welfare sector the problems resulting from population development will mainly be centered around the elderly. The older segment of the population are large consumers of health care and social services, as well as of welfare benefits, since these are their primary means of support. More pressure will be placed on government funding, at the same time as the burden of private care will increase. One question which is not discussed in the report, is whether future population development will lead to an even wider gap between the generations.

In the housing sector, population development will eventually influence the total need for new construction. On the other hand changes in age structure and family pattern will lead to increased demands for certain kinds of housing. There may also be new requirements for housing and residential environments to satisfy.

\section{Action aimed at influencing population development}

The age structure of the population will change considerably during the coming years independent of whether the birth rate is influenced through government intervention. These changes will entail great challenges for social planners and for public financing. The consequences of these changes must be incorporated into ongoing planning as soon as possible in order to provide the basis for work on more long-range perspectives in the various sectors.

Another question is whether the birth rate can be influenced through government intervention. The population committee is uncertain of whether various measures would effect birth rate development. On the other hand the committee is of the opinion that the consequences of rapid and radical changes in the age structure of the population and in the size of local populations would be so extensive and so difficult to handle that in the future any great fluctuations in the fertility and birth rates of the population ought to be avoided, if at all possible. Even though the measures would not increase fertility, at least they would probably counterbalance any further decrease.

One necessary condition for any increase in fertility is that there is a fertility potential, in other words that families would like to have more children if condi- 
tions for raising children were more favorable. We do not have any direct answer to this question, but the questions about ideal and expected family size which were posed in the Norwegian Fertility Survey in 1977, indicated that most Norwegian women expected to have 2 or more children. In the same year the actual fertility behavior showed an average of 1.76 children per woman. This should signal a certain fertility potential.

A discussion of the various possible actions which could be implemented to influence fertility in various countries concluded that there is disagreement among scientists about whether already-tried measures have had the desired effect. Nonetheless it is a fact that fertility is higher in many of the countries which have implemented action-oriented policies than in other industrialized countries.

On the other hand, no guidelines exist for deciding the degree of action necessary to achieve a particular fertility level. It is still reasonable to assume, however, that the action has to be general enough to really improve the situation of children and of families with children, both economically and in other ways.

As mentioned above, the committee is of the opinion that it would be reasonable to carry out a policy aimed at increasing fertility. The goal ought to be to achieve the level of selfperpetuation. Although it is not certain that such a goal can be realized through government action, the measures will still improve the situation of families with children and will therefore have favorable sociopolitical effects.

The committee recommends the following courses of action:

1. An extension of fully-paid maternity leave to 1 year.

2. A substantial transfer of funds to families with small children by contributing a fixed annual sum per child. The transfers will provide the basis for voluntary reductions in working hours and will increase the possibilities for the purchase of child care services.

3. Expand the number of child care facilities to meet the need completely.

4. Increase the number of supervised hours in primary school, both per day and per year.

5. Improve home and local environments.

Several of these courses of action are especially aimed at easing the adjustment of families with children to the world of work. During recent years we have seen a strong increase in career activity among the mothers of small children. The committee believes that this trend is impossible to stop, and from the point of view of equal rights, it is not desirable to try to stop it either.

In order, then, to improve the chances of successfully combining a career with child care, thereby reducing the conflict entailed by the wish for children and the wish for a career, the committee is of the opinion that action must be taken. Extended maternity leaves, adequate child care facilities and increasing hours of supervision in primary school are effective measures. At the same time it is also necessary to make it easier to opt for alternatives other than the traditional family pattern with one wage earning partner and one partner with responsibility for the home. Under the prevailing situation, it is not always economically feasible to opt for this sort of division between child care and career.

Further expansion of child care facilities and more school supervision are both measures which improve educational opportunities for children, as well as easing the situation for parents employed outside the home.

The last recommendation, for improvement of living and local environments is directly connected to children's needs for a good and safe outside play area. A recent investigation shows that $44 \%$ of those questioned felt that they absolutely would not or would not like to let a child of 5 outside on his own because the traffic was too dangerous. This is a frightening figure. 


\section{Conclusion}

In conclusion I would like to offer a personal evaluation of the report which the committee will hopefully present soon. I believe that its greatest values is as a collection of a great amount of knowledge about demographic conditions. This can contribute to the fund of knowledge related to questions asked by politicians, planners and public administrations in general, about population development. I believe that there is a great need to integrate population development more effectively into present day planning.

The committee's recommendations for action are of a more political nature and will contribute to the political debates concerning these questions. The extent to which they will be politically realized, is difficult to estimate.

\section{Comments}

\section{BIRGITTE LIEBACH:}

Demographers too often play the role of spectators to the actual development offering but refined models to describe that part of reality that can be counted by numbers.

Those two problems, the reluctance to spell out, and to participate in the discussion of the political issues implied; and the difficulties of predicting consequences of population development where so many factors not readily indexed and quantified are at variance - those problems also apply to the work of the Norwegian Population Committee.

Though a lot of useful material has been compiled and discussed in the report, one is left with the feeling that conclusions tend to get lost in the abundance of data.

Stressing the last word of the title of today's session, Population Policy, I will start with the example of the Danish labor force. If the present employment rates are to be maintained, 175,000 new jobs must be provided for during the next 15 years, assuming entrance into the labor force at age 20 , and retirement at 60 . However, presently, almost 300,000 are already registered as unemployed. Technological development, and political endeavors to cut down on the public sector, will certainly not alleviate the unemployment problem. In this context, an increasing or decreasing number of births may have a relative minor impact. The political issue retains the problem of how to secure the right to become gainfully employed. As social scientists we should not only describe the numeric dimensions of the problem but be concerned with the social consequences as well. What will happen to a society that deprives growing proportions of its young generations of possibilities to make a decent living; what will happen to norms and values when large numbers of individuals evade the socialization processes connected with working life? It may not result in pleasant creativity only.

New technology goes along with more sophisticated forms of management. The impact of that is probably a growing polarization of the labor force: the fulltime well-educated, system-controlling and -inventing »heavy boys" and the marginal part-time employed who can barely keep up with the new techniques.

The accelerating technological development will, furthermore, be a far greater challenge for planning in the educational field, than the problems of adjusting educational resources to the changing size of new generations. 